\title{
Qual o Diagnóstico?
}

\section{APRESENTAÇÃO DO CASO}

A imagem e os traçados foram obtidos durante manobra de estimulação para-hissiana em estudo eletrofisiológico. Pergunta-se: há um comportamento de condução retrógrada nodal ou extranodal?

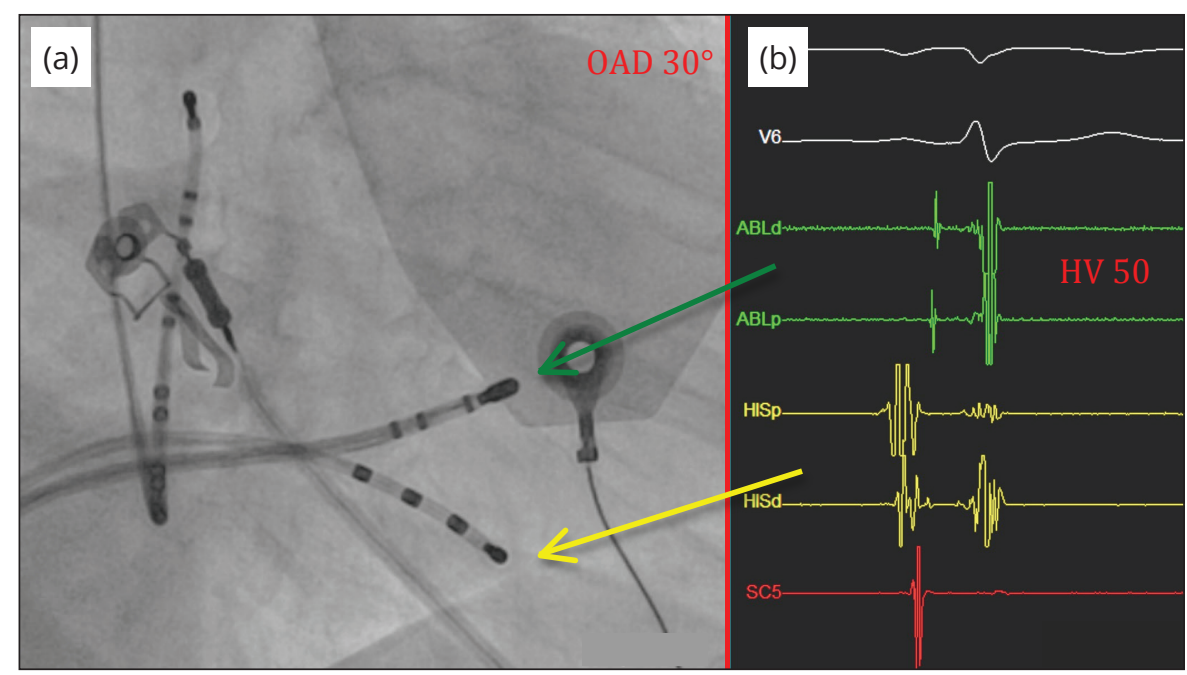

Figura 1. (a) Imagem radiológica de disposição dos cateteres durante o procedimento; (b) Eletrogramas correspondentes aos cateteres identificados a esquerda.

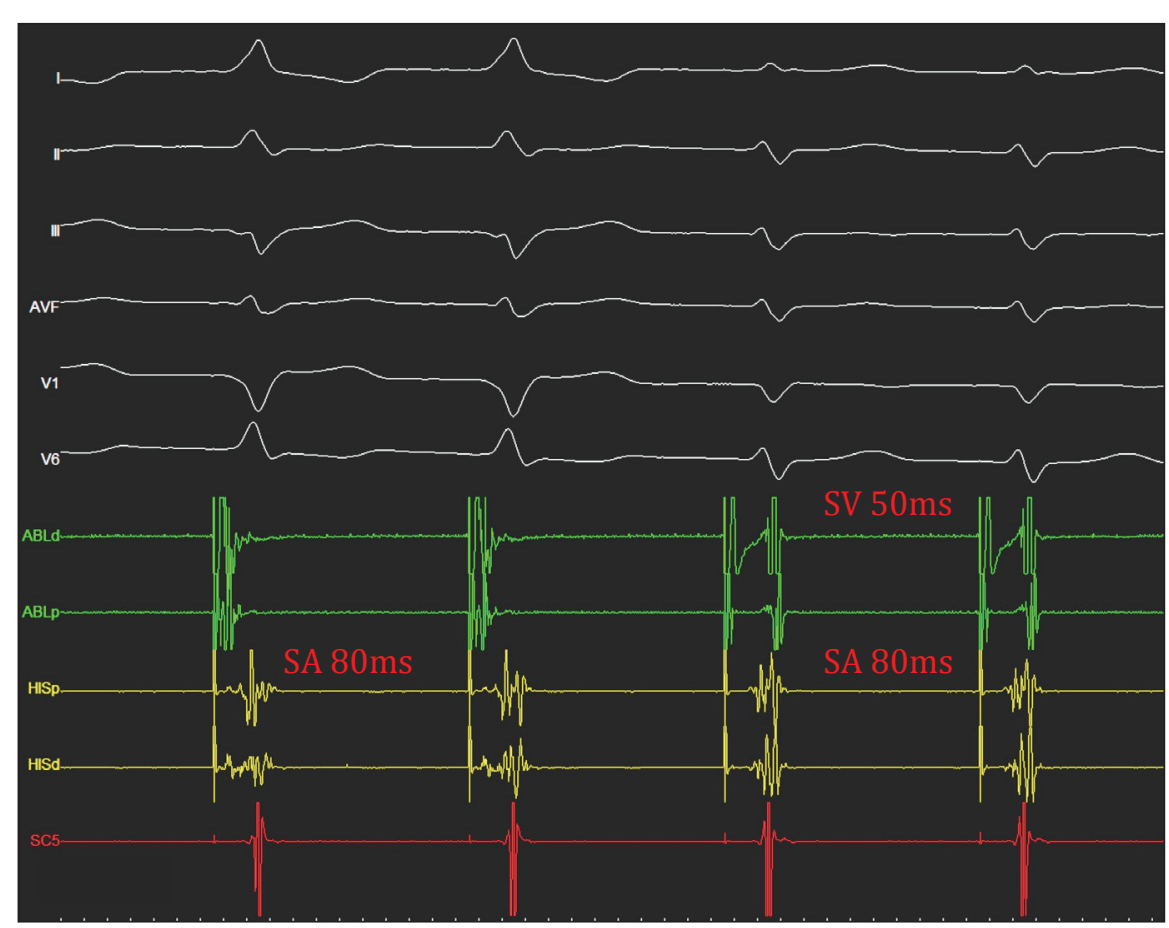

Figura 2. Traçados obtidos durante estimulação do cateter na posição do feixe de His. 


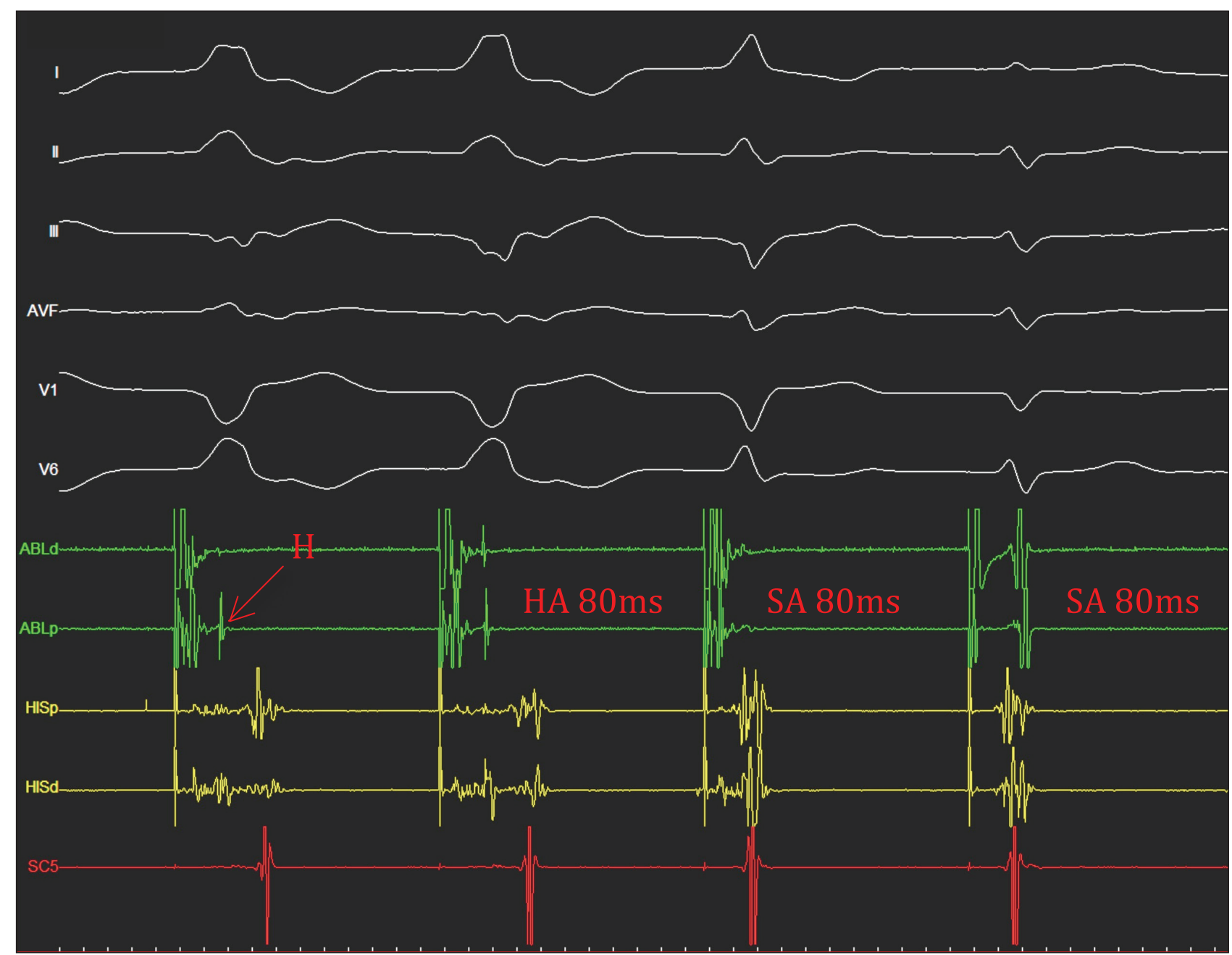

Figura 3. Três padrões eletrocardiográficos obtidos durante estimulação do cateter na posição do feixe de His.

\section{RESPOSTA}

Na Fig. 2 observa-se a estimulação para-hissiana gerando duas morfologias de complexos QRS. Os dois primeiros complexos são alargados e os dois seguintes são estreitos com morfologia semelhante aos complexos sinusais e um intervalo S-V similar ao intervalo HV de base. Em ambas as circunstâncias existe condução retrógrada ventrículoatrial, com intervalo S-A fixo de $80 \mathrm{~ms}$. A persistência do mesmo intervalo S-A durante uma estimulação parahissiana que induz diferentes padrões de complexos QRS, sejam estreitos ou alargados, em um primeiro momento, leva à definição de um comportamento de condução extranodal, ou seja, uma condução retrógrada dependente de uma via acessória. Temos que ter em mente, contudo, que os dois complexos estreitos demonstrados na Fig. 2 foram gerados por captura seletiva do feixe de His, caracterizando não uma estimulação "para-hissiana" e sim uma estimulação hissiana de fato, como fica bem caracterizado pela observação de um atraso entre o artefato de estimulação e o complexo QRS equivalente ao intervalo HV $(50 \mathrm{~ms})$. Em outras palavras, não existe o complexo de fusão gerado pela ativação ventricular decorrente da captura direta do feixe de His somado à captura do miocárdio ventricular adjacente. Portanto todo o processo de condução retrógrada nessa circunstância ocorre pelo sistema normal de condução. Os dois complexos iniciais mais alargados, por sua vez, aparentam ser complexos de fusão gerados pela captura miocárdica local e pela ativação ventricular induzida pela captura direta do feixe de His; existe assim uma estimulação direta do feixe de His, porém não seletiva. Em ambas as situações, a condução retrógrada ocorre pelo sistema normal. Essa comprovação é feita na Fig. 3, onde existe de fato a perda da captura direta do 
feixe de His. Observa-se que os dois primeiros complexos são substancialmente alargados, com um intervalo S-A claramente mais prolongado. Um potencial de His retrógrado é agora identificado, notando-se que o intervalo $\mathrm{H}$-A é precisamente de $80 \mathrm{~ms}$, sendo o prolongamento do intervalo S-A às custas do prolongamento do intervalo S-H. Ou seja, nessa circunstância o feixe de His é indiretamente ativado após a despolarização ventricular. Temos, portanto, um típico comportamento de condução retrógrada nodal.

\section{REFERÊNCIAS}

1. Hirao K, Otomo K, Wang X, Beckman KJ, McClelland JH, Widman L, et al. A new method for differentiating retrograde conduction over an accessory AV pathway from conduction over the AV node. Circulation. 1996;94(5):1027-35. https://doi.org/10.1161/01. cir.94.5.1027

2. Takatsuki S, Mitamura H, Tanimoto K, Fukuda Y, leda M, Miyoshi S, et al. Clinical implications of "pure" Hisian pacing in addition to para-Hisian pacing for the diagnosis of supraventricular tachycardia. Heart Rhythm. 2006;3(12):1412-18. https://doi.org/10.1016/j. hrthm.2006.08

\section{AUTHOR}

\section{J. Tarcísio Medeiros de Vasconcelos ${ }^{1, *}$}

Vasconcelos JTM (D) https://orcid.org/0000-0002-5152-2648

1.Centro Avançado de Ritmologia e Eletrofisiologia - São Paulo/SP - Brasil.

*Autor correspondente: tarr@terra.com.br 